\title{
Why the Fitts list has persisted throughout the history of function allocation
}

\author{
J. C. F. de Winter · D. Dodou
}

Received: 8 April 2011/Accepted: 3 August 2011 / Published online: 25 August 2011

(C) The Author(s) 2011. This article is published with open access at Springerlink.com

\begin{abstract}
Function allocation is a core activity of the human-machine systems discipline. Sixty years ago, Paul Fitts marked the outset of function allocation research with an 11-statements list. Since then numerous function allocation methods have been proposed, but strikingly the seminal Fitts list spans the entire history of this domain and continues to be cited today. In this paper, we intend to explain why the Fitts list is such a pervasive factor in function allocation research, despite having received extensive criticism. We invoke philosophy of science, and we show that the Fitts list fulfils six important criteria for appraising scientific theories: plausibility, explanatory adequacy, interpretability, simplicity, descriptive adequacy, and generalisability. Furthermore, we show that the Fitts report identified issues which decades later became known as the ironies of automation. We conclude that the Fitts list is an adequate approximation that captures the most important regularity of automation, and that the Fitts report represents an unprecedented intellectual achievement that has succeeded in its pioneering objective.
\end{abstract}

Keywords The Fitts list - MABA-MABA - Function allocation · Human-machine systems

J. C. F. de Winter $(\bowtie) \cdot$ D. Dodou

Department of BioMechanical Engineering,

Faculty of Mechanical, Maritime and Materials Engineering,

Delft University of Technology, Mekelweg 2,

2628 CD Delft, The Netherlands

e-mail: j.c.f.dewinter@tudelft.nl

\section{Introduction to function allocation}

Deciding which functions (tasks, jobs) of a humanmachine system should be allocated to the human and which to the machine (today often a computer) is one of the most essential activities within human factors research (Hancock and Scallen 1996; Price 1985). In 1951, the Fitts list (Fitts 1951) marked the beginning of function allocation research, and six decades later it continues to be cited (Fig. 1). In fact, almost any study on the topic of function allocation starts with discussing the now classic report edited by Paul Fitts. Some regard the Fitts list as an adequate starting point or a set of accepted statements, which—although it should not be applied literally, without further thought-constitutes the foundation of function allocation. At the same time, the Fitts list has received extensive criticism, ranging from it being considered an intrinsically flawed descriptive listing (Hancock and Scallen 1996), 'a useful starting point (but only that)' (Meister 1971, p. 63), to simply insufficient, outdated, static, and unable to acknowledge the organisational context and the complementarity of human and machine (Bye et al. 1999; Clegg et al. 1989; Hoffman et al. 2002; Jordan 1963). Despite the severe criticisms, according to a review article having collected the opinions of a dominant group of practitioners involved in the application of function allocation methods in systems design, the Fitts list (or variants thereof) is still the most widely used function allocation technique (Older et al. 1997).

This article sets out to explain why the Fitts list has been such a pervasive factor throughout the history of function allocation research. We argue that the Fitts list can be regarded as a function allocation theory, and we invoke philosophy of science to show that the Fitts list fulfils the criteria for appraising scientific theories, namely 


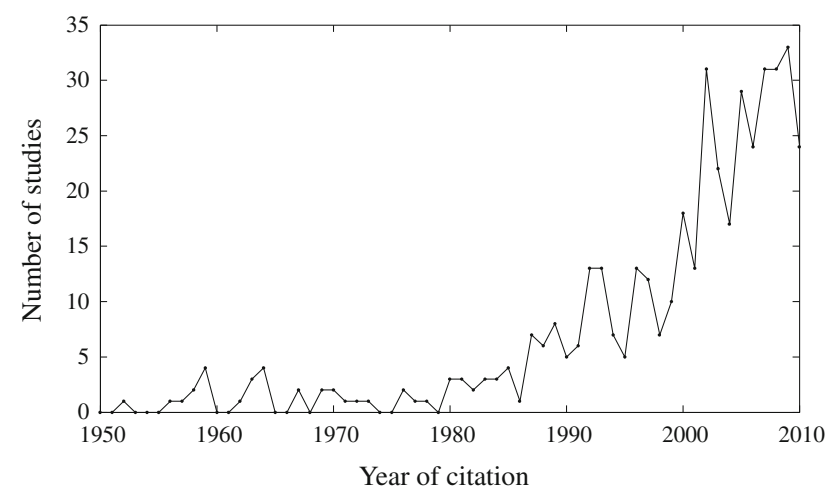

Fig. 1 Annual number of citations of the terms: 'Fitts list'; 'MABAMABA'; 'HABA MABA'; 'men are better at' and 'machines are better at'; 'humans are better at' and 'machines are better at'; 'man are better at' and 'machines are better at'; or citing the original Fitts report (1951). Irrelevant references have been manually removed. The figure was derived using Google Scholar, which includes reports that cannot be retrieved by other bibliographical databases and therefore offers a clearer view of the historical trend

plausibility, explanatory adequacy, interpretability, simplicity, descriptive adequacy, and generalisability.

\section{What is the Fitts list?}

The Fitts list is a list of 11 statements about whether a human or a machine performs a certain function better (Table 1; Fig. 2). In the Fitts list-also known by the acronym MABA-MABA ('Men are better at, Machines are better at'), first appeared in 1970 (Rappaport 1970) and more regularly since the 1980s (Parsons 1981; Price 1985)_human and machine are construed as actuating and information processing systems with different capabilities, on the basis of which it is possible to determine what should be automated and what not. In its literal interpretation, the Fitts list recommends that those functions that are better performed by machines should be automated, while the other functions should be assigned to the human operator.
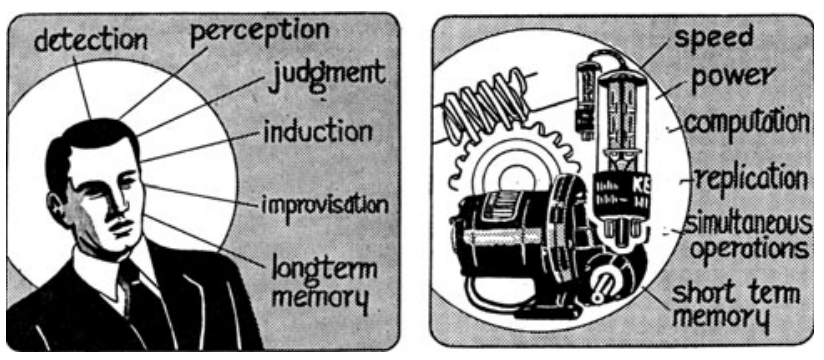

Fig. 2 Illustrations of the Fitts list taken from the original 1951 report (Fitts 1951, pp. 7-8)

The Fitts list is treated in Chap. 3, entitled 'Some basic questions in designing an air navigation and traffic control system', of an 84-page report that aimed to be a 'pioneering effort' (Fitts 1951, p. iii; cover letter by M.S. Viteles, chairman of the NRC Committee on Aviation Psychology) for human engineering research and to have a beneficial effect on research and plans for future air traffic control systems. The report consists of nine chapters and three appendices, and covers various topics, including communication, displays, systems research, and proposals for future research. Paul Fitts was the editor of the report, which had nine more authors (A. Chapanis, F. C. Frick, W. R. Garner, J. W. Gebhard, W. F. Grether, R. H. Henneman, W. E. Kappauf, E. B. Newman, and A. C. Williams, Jr.), who 'are recognised today, with Fitts, as some of the 'founding fathers' of human factors science' (Hancock and Scallen 1996, p. 25). A further 25 people in aviation, engineering, and research were also acknowledged to have contributed to draft versions of the report and group meetings.

As explained in the report, the aim was to 'search for a general answer to the problem of dividing responsibility between men and machines' (p. 6) while not 'trying to be unduly specific' (p. 11). Although the authors were clearcut by saying that 'many of the facts that we know about human beings are pertinent to decisions about the division of labour between men and machines' (p. 11, italics added), and by considering 'the roles men and machines

Table 1 The original Fitts list (Fitts 1951, p. 10)

Humans appear to surpass present-day machines in respect to the following:

1. Ability to detect a small amount of visual or acoustic energy

2. Ability to perceive patterns of light or sound

3. Ability to improvise and use flexible procedures

4. Ability to store very large amounts of information for long periods and to recall relevant facts at the appropriate time

5. Ability to reason inductively

6. Ability to exercise judgment
Present-day machines appear to surpass humans in respect to the following:

1. Ability to respond quickly to control signals and to apply great force smoothly and precisely

2. Ability to perform repetitive, routine tasks

3. Ability to store information briefly and then to erase it completely

4. Ability to reason deductively, including computational ability

5. Ability to handle highly complex operations, i.e.

to do many different things at once. 
should have in the future air navigation and traffic control system' (p. 10, italics added), at the same time they were hesitant to draw definite conclusions. For example, it was pointed out that 'a listing of those respects in which human capabilities surpass those of machines must, of course, be hedged with the statement that we cannot foresee what machines can be built to do in the future' (pp. 6-7). Furthermore, the authors recognised that technical feasibility, economic issues, training, maintenance of skills, job life, equipment maintenance, and calibration may also be relevant to function allocation.

In other words, the aim of the Fitts list was to make general statements about future function allocation, and it was not meant 'as a kind of gospel' or 'the function allocation counterpart of Moses' 10 commandments, or Luther's 95 theses' (Sheridan 2000, p. 203) as many human factors engineers have taken it.

\section{The Fitts list as a scientific theory}

Fuld (2000) argued that function allocation 'is a useful theory but not a practical method' (p. 231). We point out that the very purpose of science is theory development and the organisation of knowledge in the form of testable explanations, rather than merely being a practical method. In this article, we regard the Fitts list as a scientific theory, and from this perspective, its aim is to explain (or predict) allocation of function decisions already made, not to be used to guide engineering decisions. A function allocation theory should have broad generalisability and apply to a rich variety of real human-machine systems, and at the same time it should accurately describe which functions should be allocated (or are currently allocated) to human and machine.

Below, we invoke philosophy of science to help in judging the adequacy of the Fitts list as a scientific theory, and to explain why the Fitts list has been such a persistent factor throughout the history of function allocation. Three of the most commonly used axiological values in evaluating the appropriateness of scientific theories are precision, generality, and simplicity (Cutting 2000; Popper 1959; Speekenbrink 2005), although other values are regularly included as well. For example, Kuhn (1977) listed five criteria, sometimes designated as 'The Big Five': accuracy, consistency, scope, simplicity, and fruitfulness. In this article, we use a similar, but more comprehensive, set of criteria for appraising theories (models), which was composed for the cognitive sciences. This set was originally proposed by Jacobs and Grainger (1994), and later adapted by Pitt et al. (2002):

(a) Plausibility: Are the assumptions of the model plausible? (b) Explanatory adequacy: Is the theoretical explanation reasonable and consistent with what is known?

(c) Interpretability: Do the model and its parts make sense? Are they understandable?

(d) Simplicity: Does the model capture the phenomenon in the least complex manner?

(e) Descriptive adequacy: Does the model provide a good description of observed data?

(f) Generalisability: Does the model predict well the characteristics of new, as yet unobserved data?

The Fitts list can be argued to fulfil these criteria for appraising scientific models, each of which is addressed below.

\subsection{Plausibility}

The Fitts list makes various assumptions. The psychological needs of the human (affective and emotional requirements, job satisfaction, motivation, fatigue, stress, working under time pressure), temporal effects (learning, contextual variations), individual differences, safety, economic utility, availability, maintainability, the rapid evolution of technology, social values, the iterative design process, task complexity and interconnectedness between functions, as well as the organisational and cultural context, are all not modelled (e.g. Chapanis 1965; Clegg et al. 1989; Drury 1994; Greenstein and Lam 1985; Hancock and Scallen 1996; Price 1985; Sanders and McCormick 1987). Furthermore, the possibility that there will be tasks that neither machines nor humans can do well, or that both can do equally well, is ignored (Clegg et al. 1989; Price 1985). The fact that the Fitts list does not take into account dynamic allocation has also been pointed out by many: 'Frustration with the MABA-MABA approach led to a very simple insight. Why should function, tasks, etc. be strictly allocated to only one performer? Aren't there many situations whether either human or computer could perform a task acceptably? ...This insight led to identification of the distinction between static and dynamic allocation of functions and tasks' (Rouse 1994, p. 29, as quoted by Inagaki 2003). Hancock and Scallen (1996) argued against this acontextuality of the list by stating that 'at all points in the design process, the allocation problem is chronically underspecified. That is, there is never sufficient knowledge of the situation so that all tasks can be described in Fittslike terms and apportioned respectively' (p. 27).

Researchers dissatisfied by the general nature of the Fitts list have proposed extended and fine grained models of function allocation. Today, numerous fine-grained function allocation models can be found in the literature (for overviews, see Older et al. 1997; Parasuraman et al. 2000), including variations and extensions of the Fitts list (Bekey 
1970; Chapanis 1960; Ip et al. 1990; Sanders and McCormick 1987; Swain and Guttman 1980; US Department of Defense 1987), qualitative or quantitative multicriteria analyses (Meister 1987; Papantonopoulos 2001), expected value analyses (Sheridan and Parasuraman 2000), flow charts to assist in the design process (Malone and Heasly 2003), mental workload analyses and psychophysiological techniques (Hancock and Chignell 1988; Pope et al. 1995; Prinzel et al. 2003; Reising and Moss 1986; Wei et al. 1998), intent inferencing models (Geddes 1985; Govindaraj and Rouse 1981; see Parasuraman et al. 1992 for an overview), cognitive models (Corker et al. 1997; Degani et al. 1999; see Parasuraman 2000 for an overview), network optimisation (Shoval et al. 1993), and queuing theory (Chu and Rouse 1979; Rouse 1977; Wu et al. 2008). The focus has shifted towards dynamic task allocation (Byrne and Parasuraman 1996; Debernard et al. 1992; Greenstein and Lam 1985; Hancock and Scallen 1996; Kantowitz and Sorkin 1987; Parasuraman et al. 1996; Rencken and Durrant-Whyte 1993; Rieger and Greenstein 1982; Rouse 1988; Scerbo 2007; Sharit 1996), and it is increasingly recognised that automation is not a zero-sum game but can be designed for different levels of human or machine authority and for different processing stages, such as information acquisition, information analysis, decision making, and action implementation (Endsley and Kaber 1999; Parasuraman et al. 2000).

Function allocation models are often evaluated in terms of the number of requirements fulfilled (cf., Older et al. 1997). Consequently, it is tempting to increase the model's complexity such that it captures a greater variability, for example by including dynamic allocation, trade-offs, and iterative design. However, the fine-grained function allocation models specified above tend to be restricted in scope. In contrast to the Fitts list, they address specific areas, such as when to switch between human and machine as a function of human workload and task accuracy, and specific applications, for example, the ground collision avoidance system tested on fighter aircraft (Hardman et al. 2009). Our observations here are in line with a review about quantitative models in automation by Parasuraman (2000), which concluded that 'the price of quantification may be a reduction in generality' (p. 945).

Furthermore, many of the newly proposed function allocation models have limited validity, and have been evaluated in laboratory environments only. As Hollnagel and Cacciabue (1999) rightly pointed out, it is necessary to stay in touch with reality: 'Investigations that are driven by laboratory and experimental concerns all too easily end up by looking at phenomena that are derived from the theories and models alone. While such investigations may be valuable to determine whether the theories are good theories, in the sense that they can be used to make predictions, they do little to determine whether the theories are valid, i.e. whether they are about real phenomena' (p. 5). Importantly, several quantitative function allocation models require complicated calculations even for simple tasks, and do not taken into consideration the contextual reality (Parasuraman et al. 1992). For example, Wu et al. (2008) used a queuing network-model human processor to dynamically control the delay times between messages of in-vehicle systems presented to car drivers. Their approach relied on intricate calculations from a cognitive model to provide a numeric estimate of human workload as a function of age, speed, and curvature of the road, as well as a message controller determining optimal delay times between messages. Although their approach provides a precise quantitative estimate of workload, it can be questioned whether their calculations will be valid outside the laboratory environment, in which drivers are subjected to many environmental influences.

We argue that it is illusory and objectionable to expect that a scientific model should capture all the variables described above. Function allocation models should not gain credence merely because they include so many variables that any possible case can be described. The inappropriate tendency of researchers to strive for perfect-fit models has also been recognised by Roberts and Pashler (2000): 'The use of good fits as evidence is not supported by philosophers of science nor by the history of psychology; there seem to be no examples of a theory supported mainly by good fits that has led to demonstrable progress' (p. 358). Scientific models are always imperfect to a certain degree in their attempt to maintain predictive validity and to parsimoniously capture the phenomenon of interest (e.g. MacCallum 2003).

What is important in terms of scientific adequacy is whether the assumptions made by a model are plausible. The assumptions of the Fitts list are plausible because they have managed to capture the most important regularity of automation: if the machine surpasses the human, the function must be automated; if not, it does not make sense to automate. The Fitts list states that the primary (but not necessarily the only) driving force behind automation should be performance: precision, power, speed, cost. These are factors that Sheridan (2004) called 'the obvious advantages of automation' (p. 163), while Wickens (1992) similarly explained that the purpose of automation is improving performance, namely: 'performing functions that the human operator cannot perform because of inherent limitations ... performing functions that the human operator can do but performs poorly or at the cost of a high workload ... augmenting or assisting performance in areas in which humans show limitations' (pp. 531-532). 


\subsection{Explanatory adequacy}

The Fitts list is internally consistent in the sense that its 11 statements are diverse and non-contradictory. The Fitts list has a solid theoretical basis because it was developed 'on the basis of what psychologists know at the present time about the limiting characteristics of human capacity and performance' (p. 5), including overload, stress, fatigue, inattention, boredom, and short-term memory, and it used an information-processing approach (or communication theory in the terms used in the report), a dominant paradigm within cognitive psychology and human factors research (Proctor and Vu 2010). Even some of the strongest critics of the Fitts list recognised that the comparative nature of human and machine is theoretically an elegant solution to the allocation of functions and that 'the facts to be found in all the existing versions of the Fitts list are all correct' (Jordan 1963, p. 162).

\subsubsection{The rejection of comparability}

A number of researchers have criticised the theoretic foundations of the Fitts list by arguing against its elementaristic (atomistic, reductionistic, materialistic, mechanistic or information processing) character that forces a description of humans based on machine capabilities and human limitations. They have suggested that the Fitts list implies separation and comparability of human and machine, and that complementarity is what is important instead (Campbell and Essens 1996; Goom 1996; Fallon 2006; Jordan 1963; Hoffman et al. 2002; Hollnagel and Bye 2000; Kantowitz and Sorkin 1987). As Hancock (2009) noted: 'For a variety of reasons, although this endeavour is well intentioned, this bipartite approach is unlikely to succeed either in principle or in practice. In principal it is a fallacious approach since it acts to dichotomize human and machine in the very instances where the human-machine linkage should be the unit of concern' (p. 100).

A growing chorus of researchers favouring the complementarity viewpoint have found resort in theories that appraise overall function congruence and function matching with the aim to fulfil higher-order commitments such as maintaining control and resilience (Dekker and Hollnagel 1999; Dekker 2011; Hollnagel 2004; Hollnagel et al. 2006; McCarthy et al. 2000). The focus herein is on the complexity and emergent behaviour of systems and on the importance of reciprocal relationships and complementarity (as well as joint work, teamwork, team play, partnership, cooperation, collaboration, joint performance, respect or symbiosis) between human and machine (Bye et al. 1999; Christoffersen and Woods 2002; Dekker 2011; Downs et al. 1988; Grote et al. 1995; Hancock 1993; Hoc 2001; Leveson 2004; Malin et al. 1991). A more extreme form of these theories entails the complete rejection of the notion of an a priori allocation of functions. In a series of articles, Dekker and Woods (2002), Dekker and Hollnagel (2004) and Hollnagel and Woods (2005) rejected function allocation completely, and the Fitts list in particular, on the grounds that it relies on the so-called 'substitution myth' (a term originally proposed by Sarter et al. 1997, p. 1) and the 'false idea that people and computers have fixed strengths and weaknesses' (Dekker and Woods 2002, p. 241). They argued that 'capitalizing on some strength of computers does not replace a human weakness. It creates new human strengths and weaknesses-often in unanticipated ways' (Dekker 2005, p. 162). Dekker and Woods recommended that 'system developers abandon the traditional 'who does what' question of function allocation' (p. 243) and consider how to turn automated systems into effective 'team players' that coordinate work. These provocative commentaries by Dekker and others represent the apex of a move away from human-in-the-loop control and borrowed engineering models towards supervisory and cognitive control of increasingly complex systems (Hancock 2009; Hollnagel and Cacciabue 1999; Sheridan 2000, 2004). As explained by McCarthy et al. (2000), the field has seen a 'shift from a reductionist separation of qualitatively different humans and machines, to an attempt at their integration in sociotechnical systems and other systemic approaches' (p. 198). This 'giant swing away from simpler human functions used with proceduralized equipment to much more complex cognitive enterprises' (Meister 1999, p. 222) is driven by a raft of new technologies (Byrne and Gray 2003), in particular the computer, which have changed the role of human operators from manual control to monitoring and directing of automation (Sheridan 2004).

Theories focusing on complementarity are undoubtedly useful because they provide broad insight into the variables that need to be considered in an iterative multivariate design process. However, they do not provide explicit answers as to whether a function should be automated or not. They are also relatively immune to scientific scrutiny, as they cannot be compared in terms of goodness of fit and the degree of falsifiability. In response to Dekker and colleagues, Lintern (in press) argued that abandoning a concrete interest in function allocation cannot be taken seriously if one wants to engage with engineers and other design communities. Sheridan (2004) has also pointed out that the meaning of human-machine cooperation is yet to be worked out in terms useful to humans. It is noteworthy that the authors of the Fitts report already acknowledged the importance of a systems approach, but also recognised the criterion problem, and that a reductionist strategy is required: 'Requirements such as safety and efficiency define the goal, or ultimate criteria, for which the system is designed. However, the researcher usually cannot deal directly with 
ultimate criteria but must seek intermediate or proximate indices-of-merit for various parts of the system' (p. xii).

\subsubsection{The paradox of comparability}

Some researchers have attempted to invalidate the Fitts list on theoretical grounds by pointing out that when human functions are described in mechanical terms, it is always possible to generally build a machine that could perform more efficiently than the human (Hancock and Scallen 1996). This will inescapably lead to the design philosophy to 'design the man out of the system' (Jordan 1963, p. 162). As Jordan further explained it, 'to the extent that man becomes comparable to a machine we do not really need him any more since he can be replaced by a machine' (p. 162), and Reason (1987), 'the credibility of Fitts List foundered on a simple paradox: If a task could be described exactly (i.e. in mathematical terms), then a machine should perform it; if not, it could only be tackled using the ill-defined flexibility of a human being' (p. 468). Ironically, ahead of his critics, Fitts (1962) had already recognised the same paradox: 'If we understand how a man performs a function, we will have available a mathematical model which presumably should permit us to build a physical device or program a computer to perform the function in the same way (or in a superior manner). Inability to build a machine that will perform a given function as well as or better than a man, therefore, simply indicates our ignorance of the answers to fundamental problems of psychology' (p. 34).

It can be argued that the paradox is fallacious, since the Fitts list (1951) explicitly acknowledged that humans surpass machines in aspects that are uniquely human and cannot be described mechanistically. For example, it was stated that 'automatic computers are superior in speed and accuracy to human brains in deductive reasoning, but no success has been attained in constructing a machine which can perform inductive reasoning' (Fitts 1951, p. 8), and that 'human engineering, if it is to escape the dilemma of the old time and motion study engineering, must guard against exclusive use of the 'machine' model in its theory of human behavior' (Fitts 1951, p. v, quote from T Gordon in the editorial forward by MS Viteles). In other words, the criticism that the Fitts list implies that technology determines the language of attributes (Dekker and Woods 2002) or that 'technology (with the right capabilities) can be introduced as a simple substitution of machines for people' (Woods 2002 , p. 15) is false, precisely because the unique heuristic human capabilities are such a central theme of the list.

\subsection{Interpretability and simplicity}

The comprehensibility of the Fitts list is perhaps one of the key reasons behind its success. It does not contain complex equations, interconnected functions, or other forms of complexity. According to Sheridan (2004), "no other allocation model has replaced it in terms of simplicity and understandability' (p. 60). The only simpler function allocation formulations we could find were: 'humans should be left deal with the 'big picture', while the computer copes with the details' (Sheridan 1997, p. 91), and 'men are flexible but cannot be depended upon to perform in a consistent manner whereas machines can be depended upon to perform consistently but they have no flexibility whatsoever' (Jordan 1963, p. 163), both representing the Fitts list in a reduced form.

\subsection{Descriptive adequacy}

The categorisation in the Fitts list is qualitative (not numeric), but indicates the direction of the effect on specific comparisons. It is therefore more specific than many other function allocation methods, such as flow charts, which mention variables that should be taken into consideration but do not provide explicit answers with respect to what to automate and what not to automate.

The predictions of the Fitts list are in line with empirical data about how automation is usually implemented in actual human-machine systems, such as in aviation, robotics, and car driving. Indeed, 'in present systems, the machines (computers) usually take care of data acquisition and automatic controls, whereas the operators are left with the tasks of state identification, diagnosis, planning and decision making' (Hollnagel and Cacciabue 1999, p. 3) and this allocation is so embedded in our modern-day thinking that it can be regarded as obvious (Sheridan 2004). As Sheridan and Verplank (1978) first stated 25 years ago (see also Sheridan 2004), it is the lowest-entropy tasks in particular (routine, repetitive tasks) that are automated, whereas the high-entropy tasks are left to the human operator, which is in agreement with the Fitts list. This automation principle was already discussed in the Fitts report: 'In general, machines excel humans in the kinds of things we have already turned over to them in our society-especially tasks requiring great strength, and tasks of a very routine nature' (p. 8).

\subsection{Generalisability}

The Fitts list applies to a range of different functions, both physical and mental. Furthermore, and more arguably, the Fitts list is generalisable over time. When published in 1951, there were few computers (note the vacuum tube in Fig. 2) and the human factors discipline had only recently been established. Some have argued that it is no longer valid because machines have surpassed humans in many more categories not mentioned in the original Fitts report 
(Chapanis 1965; Kantowitz and Sorkin 1987; Parasuraman et al. 2008). Indeed, computers have become a billion times faster since 1951 (e.g. NUTD's Tianhe-1A, with a speed of 2.5 petaflops, deployed in 2010 and IBM's Sequoia, with 20 petaflops, expected later this year; see also Moore's law; Kurzweil 2005; Moore 1965), with a speed of response to signals down to the sub-picosecond (e.g. optical gates, Hulin et al. 1986; atomic clock with an accuracy of 1 ns per day), inductive reasoning having been introduced into computers in the form of machine learning, and computer statistical prediction competing with human judgement (Grove et al. 2000). Computers now surpass humans in various perceptual and cognitive activities under certain circumstances, including playing chess and face recognition (O'Toole et al. 2009), lip-reading (Hilder et al. 2009), or answering basic knowledge questions (Ferrucci 2010).

Despite all these developments, the promises of strong artificial intelligence set forth in the 1960s have not been fulfilled. In highly automated systems, the role of the human is to keep track the bigger picture by perceiving patterns, inductive reasoning, and improvisation (Sheridan 2004), which is in accordance with the Fitts list. Even in aviation, one of the most automated disciplines (Sheridan 2004 , p. 14), it is anticipated that the role of the human pilot will remain important for the foreseeable future (Mulder 2009). This is in line with what the Fitts report predicted 60 years ago: 'It appears likely, that for a good many years to come, human beings will have intensive duties in relation to air navigation and traffic control' (Fitts 1951, p. 11).

\section{A final word on the Fitts list}

Recent research emphasises the fact that automation introduces various problems such as behavioural adaptation, mistrust and complacency, skill degradation, degraded situation awareness, problems when reclaiming control and disruption to mental workload. Indeed, one of the difficulties of function allocation is that automation changes the nature of human work, often in ways unanticipated by designers (Bainbridge 1983; Dekker 2005; Parasuraman and Riley 1997), issues which have been referred to as the ironies of automation (Bainbridge 1983). Furthermore, as mentioned in Sect. 3, automation is not an all-or-nothing phenomenon but can take place at different levels and stages of machine authority (Endsley and Kaber 1999; Parasuraman et al. 2000).

Indeed, these issues are not modelled in the Fitts list. However, the Fitts report identified these issues, decades before they truly manifest themselves, while not receiving credit for these predictions.
- The Fitts report was concerned with reclaiming control when automation fails: 'We suggest that great caution be exercised in assuming that men can successfully monitor complex automatic machines and 'take over' if the machine breaks down' (Fitts 1951, p. 11), while recognising the importance of situation awareness: 'The human should be prepared to take over critical functions of air-traffic control in case of emergency. But a man cannot make intelligent decisions in an emergency unless he has an adequate understanding of the traffic picture at the moment of the emergency and for a short time preceding it' (p. 6).

- The Fitts report was concerned with the phenomenon of skill degradation. For example, the report explained that 'tasks can be set up so that human operators eventually become deficient in certain important skills which are infrequently used. As an illustration, a pilot who relies too much on the auto-pilot may lose some of his skill in manual control, or one who routinely uses automatic landing equipment may lose his skill in making manual landings' (p. 10), and concluded that 'activity ... is conducive to learning and maintenance of proficiency' (p. 6). A 1998 report 'The future of air traffic control: Human operators and automation', written by a panel of human factors specialists, with remarkably similar objectives to the 1951 Fitts report, reached similar conclusions. For example, it reported that if controllers find these advisories to be effective in controlling the airspace and come to rely on them, their own skill in resolving aircraft conflicts may become degraded' (Wickens et al. 1998, p. 36), and it concluded that research is urgently needed to examine the consequences of skill degradation.

- The Fitts report was concerned with the idea that automation changes the nature of work, which is striking, considering that it was not until the 1970s that computers indeed had a dramatic effect on humanmachine systems (Sheridan 2004) and that research areas such as supervisory control and cognitive engineering appeared. It stated that: 'Another possibility is that the human may routinely perform certain critical functions, leaving the major work of the system to semi-automatic machinery. If this turns out to be the case, then long-range research on human functions would centre about those higher-level mental functions we call reasoning, judgment, planning, and decision making' (p. 5).

- The Fitts report was concerned with different levels of automation. In a section considering possible roles of the human operator in future air traffic control and navigation systems, a distinction was made between 1. fully automatic control, 2. automatic control with human monitoring, 3. semi-automatic control supplemented by 
human performance of critical functions, and 4. primary control by human operators who would be assisted by effective data analysis, data transmission, and data display equipment.

- The Fitts report recognised the importance of keeping the human involved. For example, the report concluded: 'Human tasks should provide activity. The roles of the human operators in the future air navigation and traffic control system should be active rather than passive ones. Activity in any task is conducive to alertness, and helps to insure that the human will keep abreast of the situation' (p. 6). Contemporary research in air traffic control and situation awareness reaches rather similar discussions. For example, in an article about automation in future air traffic management, it was stated that 'operators have a better mental model or awareness of the system state when they are actively involved in creating the state of the system than when they are passively monitoring the actions of another agent or automation (Endsley, 1996; Endsley \& Kris, 1995)' (Metzger and Parasuraman 2005, p. 37).

\section{Conclusion}

Much has been written about function allocation and numerous researchers have refined existing models or have introduced their own. Some of these methods focus on complementarity of human and machine, and socio-technical aspects, while other methods have a more restrictive orientation, focusing on, for example, computational models for dynamic task allocation. In light of this diverse and overwhelming amount of important research, arguing in favour of a 60 -year-old concept that has been criticised by so many may seem absurd. In fact at a later stage even Fitts (1962) mentioned that he had 'fell into the trap of trying to make a list' (p. 36) and that this effort was 'trivial and somewhat misleading' (p. 36). However, we have shown that the Fitts list-although perhaps no longer completely valid in terms of all of its 11 statements because machines have improved drastically in the last 60 years, leading to increased automation - can be argued to fulfil the conditions of plausibility, explanatory adequacy, interpretability and simplicity, descriptive adequacy, and generalisability. This may explain the pervasiveness of the list throughout the history of function allocation research. As pointed out by Jacobs and Grainger, there are, of course, other dimensions along which models or theories may be evaluated. Examples of other categories that may be informative are modifiability, research generativity, equivalence class, or completeness of the models.

In this study, we further argued that many of the discussions about the ironies of automation are themselves ironic, because they were already recognised in the Fitts report, decades before computers became commonplace. On closer inspection, we agree that the 1951 Fitts report, 'like many other 'classics' in science ... is far more often cited than it is read' (Hancock 2009, p. 86).

The Fitts list is an approximation that describes the most important regularities of automation, and the Fitts report represents an unprecedented intellectual achievement that has succeeded in its objective to be a pioneering effort. We believe that the literature of the past decades has created an inaccurate picture of the Fitts list and we recommend that researchers cite the Fitts report in a more positive light.

Acknowledgment The research of Joost de Winter and Dimitra Dodou is supported by the Dutch Technology Foundation (STW), applied science division of the Netherlands Organisation for Scientific Research (NWO) and the Technology Program of the Ministry of Economic Affairs.

Open Access This article is distributed under the terms of the Creative Commons Attribution Noncommercial License which permits any noncommercial use, distribution, and reproduction in any medium, provided the original author(s) and source are credited.

\section{References}

Bainbridge L (1983) Ironies of automation. Automatica 19:775-779 Bekey GA (1970) The human operator in control systems. In: DeGreene KB (ed) Systems psychology. McGraw-Hill, New York, pp 248-277

Bye A, Hollnagel E, Brendeford TS (1999) Human-machine function allocation: a functional modelling approach. Reliab Eng Syst Safety 64:291-300

Byrne EA, Gray WD (2003) Returning human factors to an engineering discipline: expanding the science base through a new generation of quantitative methods-preface to the special section. Hum Factors 45:1-4

Byrne EA, Parasuraman R (1996) Psychophysiology and adaptive automation. Biol Psychol 42:249-268

Campbell GU, Essens PJMD (1996) Function allocation in information systems. In: Beevis D, Essens P, Schuffel H (eds) Improving function allocation for integrated systems design. Crew System Ergonomics Information Analysis Center, Wright-Patterson Air Force Base, Ohio, pp 121-135

Chapanis A (1960) Human engineering. In: Flagle CD, Huggins WH, Roy RH (eds) Operations research and systems engineering. John Hopkins Press, Baltimore

Chapanis A (1965) On the allocation of functions between men and machines. Occup Psychol 39:1-11

Christoffersen K, Woods DD (2002) How to make automated systems team players. In: Salas E (ed) Advances in human performance and cognitive engineering research, vol 2. Elsevier, Amsterdam, pp 1-12

Chu YY, Rouse WB (1979) Adaptive allocation of decision making responsibility between human and computer in multitask situations. IEEE Trans Syst Man Cybern SMC 9:769-778

Clegg C, Ravden S, Corbett M, Johnson G (1989) Allocating functions in computer integrated manufacturing: a review and a new method. Behav Inf Technol 8:175-190 
Corker K, Pisanich G, Bunzo M (1997) Empirical and analytic studies of human/automation dynamics in airspace management for free flight. In: Proceedings of the 10th international confederation of European aerospace societies conference on free flight, Amsterdam, pp 115-120

Cutting JE (2000) Accuracy, scope, and flexibility of models. J Math Psychol 44:3-19

Debernard S, Vanderhaegen F, Millot P (1992) An experimental investigation of dynamic allocation of tasks between air traffic controller and AI systems. In: Stassen HG (ed) Analysis, design and evaluation of man-machine systems. Pergamon, Oxford, pp 95-100

Degani A, Shafto M, Kirlik A (1999) Modes in human-machine systems: review, classification, and application. Int J Aviat Psychol 9:125-138

Dekker SWA (2005) Ten questions about human error: a new view of human factors and system safety. Lawrence Erlbaum, Hillsdale

Dekker S (2011) Drift into failure. Ashgate Publishing, Surrey

Dekker SWA, Hollnagel E (eds) (1999) Coping with computers in the cockpit. Ashgate Publishing, Aldershot

Dekker SWA, Hollnagel E (2004) Human factors and folk models. Cogn Technol Work 6:79-86

Dekker SWA, Woods DD (2002) MABA-MABA or Abracadabra? Progress on human-automation coordination. Cogn Technol Work 4:240-244

Downs E, Clare P, Coe I (1988) Structured systems analysis design method: application and context. Prentice-Hall, New York

Drury CG (1994) Function allocation in manufacturing. In: Robertson SA (ed) Contemporary ergonomics: proceedings of the ergonomics society's 1994 annual conference. Taylor and Francis, London, pp 2-16

Endsley MR, Kaber DB (1999) Level of automation effects on performance, situation awareness and workload in a dynamic control task. Ergon 42:462-492

Fallon EF (2006) Allocation of functions: past, present, and future perspectives. In: Karwowski W (ed) International encyclopedia of ergonomics and human factors, 2nd edn. CRC Press, New York

Ferrucci D (2010) Build Watson: an overview of DeepQA for the Jeopardy! challenge. In: Proceedings of the 19th international conference on parallel architectures and compilation techniques, Vienna, Austria

Fitts PM (ed) (1951) Human engineering for an effective air navigation and traffic control system. National Research Council, Washington, DC

Fitts PM (1962) Functions of man in complex systems. Ergon Des $1: 20-24$

Fuld RB (2000) The fiction of function allocation, revisited. Int J Hum Comput Stud 52:217-233

Geddes N (1985) Intent inferencing using scripts and plans. In: Proceedings of the first annual aerospace applications of artificial intelligence conference, Washington DC, pp 123-127

Goom MK (1996) Function allocation and MANPRINT. In: Beevis D, Essens P, Schuffel H (eds) Improving function allocation for integrated systems design. Crew System Ergonomics Information Analysis Center. Wright-Patterson Air Force Base, Ohio, pp 45-61

Govindaraj T, Rouse W (1981) Modeling the human controller in environments that include continuous and discrete tasks. IEEE Trans Syst Man Cybern SMC 11:410-417

Greenstein JS, Lam ST (1985) An experimental study of dialoguebased communication for dynamic human-computer task allocation. Int J Man-Mach Stud 23:605-621

Grote G, Weik S, Waefler T, Zoelch M (1995) Criteria for the complementary allocation of functions in automated work systems and their use in simultaneous engineering projects? Int J Ind Ergon 16:367-382

Grove WM, Zald DH, Lebow BS, Snitz BE, Nelson C (2000) Clinical versus mechanical prediction: a meta-analysis. Psychol Assess 12:19-30

Hancock PA (1993) On the future of hybrid human-machine systems. In: Wise JA, Hopkin VD, Stager P (eds) Verification and validation of complex systems: human factors issues. Springer, Berlin, pp 61-85

Hancock PA (2009) Mind, machine and morality. Toward a philosophy of human-technology symbiosis. Ashgate Publishing, Surrey

Hancock PA, Chignell MH (1988) Mental workload dynamics in adaptive interface design. IEEE Trans Syst Man Cybern 18:647-658

Hancock PA, Scallen SF (1996) The future of function allocation. Ergon Des Q Hum Factors Appl 4:24-29

Hardman N, Colombi J, Jacques D, Hill RR (2009) An evaluation of collision avoidance technologies using empirical function allocation. Int J Appl Aviat Stud 9:133-154

Hilder S, Harvey R, Theobald B (2009) Comparison of human and machine-based lip-reading. In: Proceedings of the international conference on auditory-visual speech processing, Norwich, pp 86-89

Hoc J-M (2001) Towards a cognitive approach to human-machine cooperation in dynamic situations. Int $\mathrm{J}$ Hum-Comput Stud 54:509-540

Hoffman RR, Ford KM, Feltovich PJ, Woods DD, Klein G, Feltovich A (2002) A rose by any other name...would probably be given an acronym. IEEE Intell Syst 17:72-80

Hollnagel E (2004) Automation and human work. In: Sandom C, Harvey RS (eds) Human factors for engineers. The Institution of Engineering and Technology, Herts, pp 113-136

Hollnagel E, Bye A (2000) Principles for modelling function allocation. Int J Hum-Comput Stud 52:253-265

Hollnagel E, Cacciabue PC (1999) Cognition, technology \& work: an introduction. Cogn Technol Work 1:1-6

Hollnagel E, Woods DD (2005) Joint cognitive systems: patterns in cognitive systems engineering. CRC Press, Boca Rotan

Hollnagel E, Woods DD, Leveson N (2006) Resilience engineering: concepts and precepts. Ashgate Publishing, Surrey

Hulin D, Mysyrowicz A, Antonetti A, Migus A, Masselink WT, Morkoç H, Gibbs HM, Peyghambarian N (1986) Ultrafast alloptical gate with subpicosecond ON and OFF response time. Appl Phys Lett 49:749-751

Inagaki T (2003) Adaptive automation: sharing and trading of control. In: Hollnagel E (ed) Handbook of cognitive task design. Lawrence Erlbaum, Mahwah, pp 147-169

Ip WK, Damodaran L, Olphert CW, Maguire MC (1990) The use of task allocation charts in system design: a critical appraisal. In: Diaper D, Gilmore D, Cockton G, Shackel B (eds) Proceedings of Interact'90, Amsterdam, pp 289-294

Jacobs AM, Grainger J (1994) Models of visual word recognitionsampling the state of the art. J Exp Psychol Hum Percept Perform 29:1311-1334

Jordan N (1963) Allocation of functions between man and machines in automated systems. J Appl Psychol 47:161-165

Kantowitz BH, Sorkin RD (1987) Allocation of functions. In: Salvendy G (ed) Handbook of human factors. Wiley, New York, pp 355-369

Kuhn TS (1977) Objectivity, value judgment, and theory choice. In: The essential tension. The University of Chicago Press, Chicago, pp 320-339

Kurzweil R (2005) The singularity is near: when humans transcend biology. Viking, New York 
Leveson N (2004) A new accident model for engineering safer systems. Saf Sci 42:237-270

Lintern G (in press) Work-focused analysis and design. Cogn Technol Work

MacCallum RC (2003) 2001 presidential address. Working with imperfect models. Multivar Behav Res 38:113-139

Malin JT, Schreckenghost DL, Woods DD, Potter S, Johannesen L, Holloway M, Forbus KD (1991) Making intelligent systems team players: case studies and design issues. Tech Memo 104738, NASA Johnson Space Center, Houston

Malone TB, Heasly CC (2003) Function allocation: policy, practice, procedures, \& process. Nav Eng J 115:49-62

McCarthy JC, Fallon E, Bannon L (eds) (2000) Dialogues on function allocation [Special issue]. Int J Hum-Comput Stud 52

Meister D (1971) Human factors: theory and practice. Wiley, New York

Meister D (1987) Systems design, development and testing. In: Salvendy G (ed) Handbook of human factors. Wiley, New York, pp $18-42$

Meister D (1999) The history of human factors and ergonomics. Lawrence Erlbaum, Mahwah

Metzger U, Parasuraman R (2005) Automation in future air traffic management: effects of decision aid reliability on controller performance and mental workload. Hum Factors 47:35-49

Moore GE (1965) Cramming more components onto integrated circuits. Electron 38:114-117

Mulder M (2009) Aerospace human-machine systems: from safety to where? Dissertation, Delft University of Technology. http:// repository.tudelft.nl/view/ir/uuid\%3A4f9f2aa0-8d2f-4eb7-ace8a839b83aff59/

O'Toole AJ, Phillips PJ, Narvekar A (2009) Humans versus algorithms: comparisons from the face recognition vendor test 2006. In: Proceedings of the 8 th international conference on automatic face \& gesture recognition, Amsterdam

Older MT, Waterson PE, Clegg CW (1997) A critical assessment of task allocation methods and their applicability. Ergon 40:151-171

Papantonopoulos S (2001) A decision analytic model for cognitive task allocation. Tech Rep, Department of Industrial Management, University of Piraeus

Parasuraman R (2000) Designing automation for human use: empirical studies and quantitative models. Ergon 43:931-951

Parasuraman R, Riley VA (1997) Humans and automation: use, misuse, disuse, abuse. Hum Factors 39:230-253

Parasuraman R, Bahri T, Deaton J, Morrison J, Barnes M (1992) Theory and design of adaptive automation in aviation systems. Prog Rep NAWCADWAR-92033-60, Naval Air Warfare Center, Houston

Parasuraman R, Mouloua M, Molloy R (1996) Effects of adaptive task allocation on monitoring of automated systems. Hum Factors 38:665-679

Parasuraman R, Sheridan TB, Wickens CD (2000) A model for types and levels of human interaction with automation. IEEE Trans Syst Man Cybern-A Syst Hum 30:286-297

Parasuraman R, Sheridan TB, Wickens CD (2008) Situation awareness, mental workload, and trust in automation: viable, empirically supported cognitive engineering constructs. J Cogn Eng Decis Mak 2:140-160

Parsons HM (1981) Automation and engineering psychology: a look to the future. Invited address at the annual meeting of the American Psychological Association, Professional paper 7081. Human Resources Research Organisation, Alexandria

Pitt MA, Myung IJ, Zhang S (2002) Toward a method of selecting among computational models of cognition. Psychol Rev 109:472-491

Pope AT, Bogart EH, Bartolome D (1995) Biocybernetic system evaluates indices of operator engagement. Biol Psychol 40:187-196
Popper K (1959) The logic of scientific discovery. Routledge, London Price HE (1985) The allocation of function in systems. Hum Factors 27:33-45

Prinzel LJ III, Freeman FG, Scerbo MW, Mikulka PJ, Pope AT (2003) Effects of a psychophysiological system for adaptive automation on performance, workload, and the event-related potential P300 component. Hum Factors 45:601-613

Proctor RW, Vu K-PL (2010) Cumulative knowledge and progress in human factors. Annu Rev Psychol 61:623-651

Rappaport M (1970) Human factors applications in medicine. Hum Factors 12:25-35

Reason J (1987) Cognitive aids in process environments: prostheses or tools? Int J Man-Mach Stud 27:463-470

Reising JM, Moss RW (1986) 2010: the symbionic cockpit. IEEE Aerosp Electron Syst Magaz 1:24-47

Rencken WD, Durrant-Whyte HF (1993) A quantitative model for adaptive task allocation in human-computer interfaces. IEEE Trans Syst Man Cybern 23:1072-1090

Rieger CA, Greenstein JS (1982) The allocation of tasks between the human and computer in automated systems. In: Proceedings of the IEEE international conference on cybernetics and society, New York, pp 204-208

Roberts S, Pashler H (2000) How persuasive is a good fit? A comment on theory testing. Psychol Rev 107:358-367

Rouse WB (1977) Human-computer interaction in multitask situations. IEEE Trans Syst Man Cybern SMC 7:384-392

Rouse WB (1988) Adaptive aiding for human/computer control. Hum Factors 30:431-443

Rouse WB (1994) Twenty years of adaptive aiding: origins of the concepts and lessons learned. In: Mouloula M, Parasuraman R (eds) Human performance in automated systems: current research and trends. Lawrence Erlbaum: Hillsdale, NJ, pp 28-33

Sanders MS, McCormick EJ (1987) Human factors in engineering and design. McGraw-Hill, New York

Sarter NB, Woods DD, Billings CE (1997) Automation surprises. In: Salvendy G (ed) Handbook of human factors and ergonomics, 2nd edn. Wiley, New York, pp 1926-1943

Scerbo MW (2007) Adaptive automation. In: Parasuraman R, Rizzo M (eds) Neuroergonomics: the brain at work. Oxford University Press, Oxford, pp 239-252

Sharit J (1996) Allocation of functions. In: Salvendy G (ed) Handbook of human factors and ergonomics. Wiley, New York, pp 301-336

Sheridan TB (1997) Task analysis, task allocation and supervisory control. In: Helander MG, Landauer TK, Prabhu PV (eds) Handbook of human-computer interaction. Elsevier, Amsterdam, pp 87-105

Sheridan TB (2000) Function allocation: algorithm, alchemy or apostasy? Int J Hum-Comput Stud 52:203-216

Sheridan TB (2004) Humans and automation: system design and research issues. Wiley, Santa Monica

Sheridan TB, Parasuraman R (2000) Human vs. automation in responding to failures: an expected-value analysis. Hum Factors 42:403-407

Sheridan TB, Verplank WL (1978) Human and computer control of undersea teleoperators. Tech Rep, MIT Man-Machine Systems Laboratory, Cambridge

Shoval S, Koren Y, Borenstein J (1993) Optimal task allocation in task agent control state space. In: Proceedings of the IEEE international conference on systems, man and cybernetics, vol 4, pp 27-32

Speekenbrink M (2005) Consensus and methodology. Dissertation, University of Amsterdam. http://dare.uva.nl/document/13961

Swain AD, Guttman HF (1980) Handbook of human reliability analysis with emphasis on nuclear power plant applications. Rep NRC NUREG-CR-1278, Sandia Laboratories, Albuquerque, NM 
US Department of Defense (1987) Human engineering procedures guide. Rep DOD-HDBK-763, Washington, DC

Wei ZG, Macwan AP, Wieringa PA (1998) A quantitative measure for degree of automation and its relation to system performance and mental load. Hum Factors 40:277-295

Wickens CD (1992) Engineering psychology and human performance, 2nd edn. HarperCollins, New York

Wickens C, Mavor AS, Parasuraman R, McGee JP (1998) The future of air traffic control. Human operators and automation. National Academy Press, Washington, DC
Woods DD (2002) Steering the reverberations of technology change on fields of practice: laws that govern cognitive work. In: Gray WD, Schunn CD (eds) Proceedings of the twenty-fourth annual conference of the cognitive science society, pp 14-16

Wu C, Tsimhoni O, Liu Y (2008) Development of an adaptive workload management system using the queueing networkmodel human processor (QN-MHP). IEEE Trans Intell Transp Syst 9:463-475 